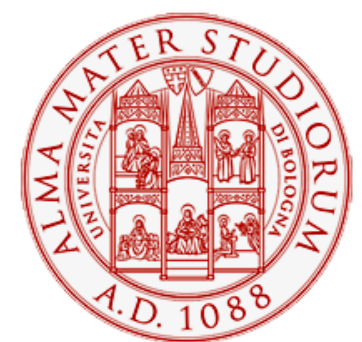

Alma Mater Studiorum - Università di Bologna DEPARTMENT OF ECONOMICS

How do Performance Targets Affect Future

Performance by Students and Schools?

Marcello Sartarelli

Alessandro Tampieri

Quaderni - Working Paper DSE N 760

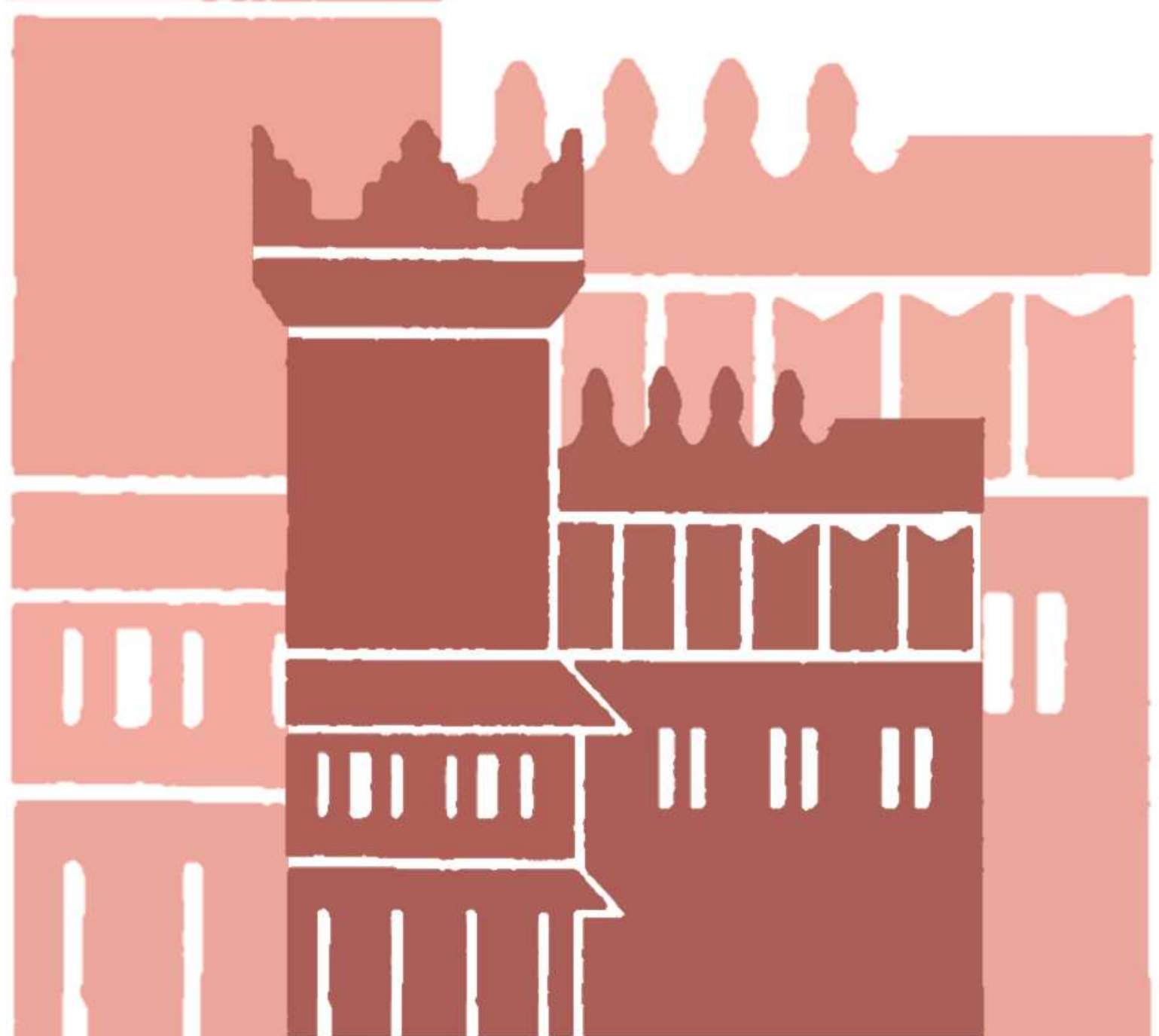




\title{
How do Performance Targets Affect Future Performance by Students and Schools?
}

\section{PRELIMINARY: PLEASE DO NOT QUOTE WITHOUT PERMISSION}

\author{
Marcello Sartarelli* \\ Alessandro Tampieri ${ }^{\dagger}$ \\ INSTITUTE OF EDUCATION \\ UNIVERSITÀ DI BOLOGNA
}

June 15, 2011

\begin{abstract}
The paper examines whether meeting performance targets in tests at school has an effect on students' subsequent achievement in education and the take-up by schools of financial support from the government for students. We build a theoretical model to describe the channels through which students' belief of their ability, as proxied by previous performance in tests, affect their current effort in preparing for a test, and how previous performance affects the effort in teaching by a school. We find that an increase in the performance target in the first test has an ambiguous effect on the effort exerted for the second test. A higher performance target in the current test increases the effort of low-ability students and teaching effort for low ability students, while it has an ambiguous effect on high ability ones. Finally, an increase in government funding per student increases the effort by students.
\end{abstract}

JEL Classification: I22, I28

Keywords: education finance, performance targets, test scores

${ }^{*}$ Institute of Education, University of London, 20 Bedford Way, London WC1H0AL, UK. Email m.sartarelli@ioe.ac.uk

'Department of Economics, University of Bologna, Strada Maggiore 45, Bologna 40125 Italy. Email alessandro.tampieri@unibo.it 


\section{Introduction}

This paper investigates how performance targets in education affect students' behaviour and subsequent actions by schools. Performance targets are popular in several dimensions of an individual's life, such as education and the labour market. Targets are important in helping individuals to build human capital or signal ability in education and at work. For example, a student may not be motivated to study if she knew that performing above average at school would not lead her to find a better job.

However, performance targets may have unintended consequences. For example, rewarding individuals only if they perform above the average level may increase the average performance in a school or a firm, although it may change individuals' beliefs about their ability by overstating true ability for those meeting a target, and viceversa for those missing the target. In addition, high ability individuals may exert little effort, as the payoff is not proportional to one's performance or effort. Potentially low motivation or performance may lead to an intervention, for example, by parents and teachers to help students. Failing this, policy decisions may help to rectify incentives and performance.

The effect of performance targets in employment contracts has been widely explored 1 Instead little is known about performance targets as incentives for students, and also for schools. If a student fails to meet an important target in test scores, this may decrease the motivation for studying. Alternatively, the student may be more motivated to study than before, obtain a high test score in the future, and perhaps choose to study a university degree. In addition, a school may exert additional effort to help the students improving their performance in future tests, and it may also obtain additional financial support by the government for each student with special education needs in a school. Conversely, a school may pay little attention to underperforming students, if this leads to no adverse consequences for the institution.

The recent increase in interest by policy-makers in the role of education in influencing students' subsequent behaviour confirms the pressing need for additional knowledge of the impact of performance target today on students' future performance and choices in education, to inform policy decisions $2^{2}$ Hence, research on the impact of incentives for students on their future behaviour and choices is of interest to policy-makers who deal with education and public policies for young individuals. The reason is that most policy research has focused on such determinants of children's education outcomes as parents' education and income $\mathrm{S}^{3}$ In contrast, little

\footnotetext{
${ }^{1}$ See Prendergast (1999) for a review of incentives and performance targets in employer-employee contracts.

${ }^{2}$ In 2001 the Department for Education in the USA funded "No Child Left Behind " (NCLB) (See "No Child Left Behind"h http://www.ncpublicschools.org/nclb/). This is a multi-billion dollar policy initiative to study the determinants of test score gaps among students of schooling age, and prevent adverse effects in adulthood for those left behind at school. It helps to address such policy issues as low employment and wage profiles over time, as well as health problems that lagging behind at school may lead to in adulthood. Since 2003 the Department for Education in the UK has funded "Every child matters", which is a similar policy initiative to NCLB, but it puts additional emphasis on well-being and fostering positive behaviour in children (see "Every child matters" in http://www.everychildmatters.gov.uk.)

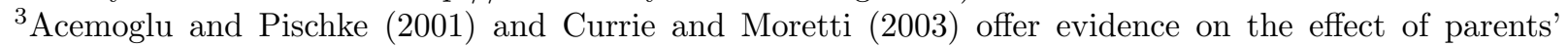
socio-economic background on children's education in the USA while Chevalier and Lanot (2002) offer similar
} 
is known about the effect of targets in education on future behaviour and choices by students and teaching strategies by schools.

We build a theoretical model to describe the channels through which changes in the performance target influence students' behaviour and actions by schools. In the model, students do not know their ability level 4 They obtain a belief about it by taking a pre-school test, and then attend school. Before completing education, they decide whether or not to exert effort in the final test. As per the school, it decides the teaching effort to exert for each student. We study the equilibrium between students and schools and the resulting test score that interaction among them leads to.

Our results show that an increase in the performance target in the first test has an ambiguous effect on the effort that is exerted in the second test. In particular, it increases the effort in the second test for the students who passed the first test, while it may decrease the effort in the second test for those who failed the first one. Moreover, an increase in the performance target in the second test increases the effort of low-ability students and the effort by schools to teach low ability students, while it has an ambiguous effect on high ability students. Finally, an increase in government funding per student increases the current effort by students. In the analysis of test scores, our result show that an increase in government funding per student increases the current test scores if the performance target is low and decreases it if the target is high.

Bandiera et al. (2009) and Azmat and Iriberri (2009) show evidence of a positive effect of disclosure of performance in tests at school on future performance, thus suggesting the policyrelevance of gaining additional knowledge of performance targets in education. Sartarelli (2011) offers a similar test for the behaviour of students, such as the probability of a police warning, and the evidence shows negative effects on behaviour, although small and little significant, of meeting performance target in test scores. Crawford and Vignoles (2010) show evidence of a negative effect of government support programs in education on achievement in the UK, while Figlio and Getzler (2002) show evidence of gaming by schools to obtain a similar type support in the USA. In related research, Cullen and Reback (2006) show evidence of actions by schools to game accountability systems in the USA.

The paper contributes to the literature on incentives for students and teachers in schools, e.g. test-based accountability, by suggesting that the implementation of programs that promote accountability may lead to effects that were unintended by a policy-maker at the design stage of a policy. This suggests that a government faces a tradeoff in the design of education policies between the richness of the outputs that an articulated policy may deliver, and the difficulties in implementing such a policy, whose unintended outcomes may or may not be desirable.

The structure of the rest of the paper is as follows. Section 2 outlines the model. Section 3 evidence in the UK.

${ }^{4}$ Gary-Bobo and Trannoy (2008) study the efficient university tuition fees where both universities and students have a noisy signal of the students' ability by assuming that students are not aware of their ability. 
describes the results and Section 4 concludes.

\section{The model}

Consider students in compulsory education in a country and normalise their number to one. Students can have high $(H)$ or low $(L)$ ability, and they do not know their ability level. We denote as $\lambda \in[0,1]$ the number of high-ability students.

Students take a test before starting school, they attend school and finally, before leaving school, they take a second test, which are are to be thought as national test $5^{5}$ Students may either exert effort or shirk in any test, that has only two possible outcomes: the student may pass $(P)$ or fail $(F)$. We denote the probability of passing one of the two tests as $v_{i j}$, where $i \in\{H, L\}$ indicates a student's ability and $j \in\{1,2\}$ indicates whether a test is the first or the second one that a student sits, according to the following mechanism:

$$
v_{i j}=\left\{\begin{array}{cc}
1 & \text { if } H \text { exerts effort } \\
\left(1-\eta_{H j}\right) & \text { if } H \text { shirks } \\
\left(1-\eta_{L j}\right) & \text { if } L \text { exerts effort } \\
0 & \text { if } L \text { shirks }
\end{array}\right.
$$

If the student has high ability and exerts effort, she will pass with probability 1 . If the student has high ability but shirks, she will pass with probability $\left(1-\eta_{H j}\right), \eta_{H j} \in(0,1)$, If the student has low ability and exerts effort, she will pass with probability $\left(1-\eta_{L j}\right), \eta_{L j} \in(0,1)$. Finally, if the student has low ability and shirks, she will pass with probability zero.

We interpret $\eta_{H j}$ and $\eta_{L j}$ as measures of performance targets, increasing which makes passing the test harder. The implicit assumption is that the performances either of a student with high ability who exerts effort or with low-ability who does not exert effort are affected only marginally by targets. This simplifies the analysis and allows us to focus on the group of students' population that is mostly affected by teaching strategies.

\section{$2.1 \quad$ First test}

We interpret the first test as one that assesses the proficiency, for example in English and Maths, of a cohort of students starting school. The test score of the first test depends on (i) the student's ability, and (ii) her effort in preparing the test.

Exerting effort for the first test is denoted by $e_{i} \in[0,1]$. For the sake of simplicity, we take both the score in the first test and the effort exerted in it as exogenous. The result of the first test determines the belief that students have about their ability when they decide whether to

\footnotetext{
${ }^{5}$ An example of such tests are the "Scholastic Assessment Test" in United States and the "National Curriculum Assessment" in United Kingdom. These tests are managed by the "Educational Testing Service" (Rourke and F. (1991)).
} 
exert effort in the second test. This is denoted by $\pi\left(i \mid \lambda, e_{i}, g_{z}\right)$, where $g_{z}, z \in\{P, F\}$ is the score in the first test.

Definition 1 A student's beliefs about her own ability which are consistent with Bayes' rule are

$$
\begin{gathered}
\pi\left(H \mid \lambda, g_{P}, e_{i}=1\right)=\frac{\lambda e_{H}}{\lambda e_{H}+(1-\lambda) e_{L}\left(1-\eta_{L 1}\right)} \\
\pi\left(H \mid \lambda, g_{P}, e_{i}=0\right)=1 \\
\pi\left(L \mid \lambda, g_{P}, e_{i}=1\right)=\frac{(1-\lambda) e_{L}\left(1-\eta_{L 1}\right)}{\lambda e_{H}+(1-\lambda) e_{L}\left(1-\eta_{L 1}\right)} \\
\pi\left(L \mid \lambda, g_{P}, e_{i}=0\right)=0
\end{gathered}
$$

if the student passed the first test, and

$$
\begin{gathered}
\pi\left(H \mid \lambda, g_{F}, e_{i}=1\right)=0, \\
\pi\left(H \mid \lambda, g_{F}, e_{i}=0\right)=\frac{\lambda\left(1-e_{H}\right) \eta_{H 1}}{\lambda\left(1-e_{H}\right) \eta_{H 1}+(1-\lambda)\left(1-e_{L}\right)}, \\
\pi\left(L \mid \lambda, g_{F}, e_{i}=1\right)=1, \\
\pi\left(L \mid \lambda, g_{F}, e_{i}=0\right)=\frac{(1-\lambda)\left(1-e_{L}\right)}{\lambda\left(1-e_{H}\right) \eta_{H 1}+(1-\lambda)\left(1-e_{L}\right)},
\end{gathered}
$$

if she did not pass it.

According to the test mechanism, a student who shirks and passes the first test has high ability with probability one. Also, a student who exerts effort but does not pass it has low ability with probability one. In those cases students know their own type after the first test. This does not happen in the other two cases (exerting effort and passing/shirking and failing).

The game starts at this point. At the first stage, the school decides the amount of teaching effort for each student. At the second stage, the student decides the amount of effort in order to study for the second test.

\subsection{Teaching effort}

Once students took the first test, they start school, irrespective of the score that they obtained. For simplicity we focus on a single school to assume away competition between schools. The school decides whether or not to exert effort in teaching them, that is denoted by $t_{i z} \in[0,1]$, and it knows students' scores in the first tests. The school also pays for each student it teaches a cost $q>0$, which we interpret as the monetary cost of hiring teachers, arranging cultural trips and offering extra courses.

If a student passes the second test, the school obtains a benefit $\mu$, because students' attainment increases their chances of pursuing further education or finding a job, and indirectly the reputation by the school for the placement of its students. A school can increase its reputation in different ways: it may derive more benefit from an increase in the job opportunities of its most able pupils, or, vice versa, of the least able ones. To depict the interaction with students in the most general way we abstract from these differences. 
If a student does not pass the second test, the school may ask the government for financial support in order to increase the support for students in a later cohort ${ }^{6}$ For each student receiving the government support $w$, the student a lower benefit than if the student obtained a high score in a test, $w<\mu$. Hence the expected payoff by the school is denoted by

$$
\Pi=N \mu+(1-N) w-T q
$$

where $N \in[0,1]$ denotes the amount of students passing the second test and $T \in[0,1]$ denotes the number of students receiving teaching.

\section{$2.3 \quad$ Second test}

The score in the second test depends on (i) the student's ability, (ii) her belief on her type, (iii) her effort in preparing the test and (iv) the school's teaching effort. The effort exerted for the second test will depend on both ability and the score in the first test. We will denote it as $e_{i z} \in[0,1]$.

If the student passes the second test she obtains a benefit $y>0$ with a probability given by the teaching effort $t_{i z}$, while exerting effort for the second test determines a utility cost $c<y$. The fact that the effort into teaching influences directly the student's benefit implies that, in the hypothetical case where the student does not receive any teaching, exerting effort with no help from school will lead to a negative expected payoff.

If the student fails the second test, her benefit is normalised to zero. Hence the student's expected payoff is given by:

$$
S=\pi\left(i \mid \lambda, e_{i}, g_{z}\right) e_{i z}\left(v_{i j} t_{i z} y-c\right)
$$

\section{Results}

We study the perfect Bayesian equilibrium of the game, which is a combination of school and students' strategies and beliefs such that both agents maximise their payoff. For simplicity, we rule out pure strategies from the analysis. On the one hand, it is little realistic that a school will deprive a student from teaching. On the other hand, scarcity in educational resources may lead the school to devote a different level of effort to students with different characteristics. It is also realistic to assume that that a student's effort $e_{i}$ is strictly between the no effort level at 0 , and the maximum level at 1 .

Proposition 1 There is a unique mixed-strategies equilibrium in the school-students game

\footnotetext{
${ }^{6}$ In the UK, English as Additional Language (EAL) or Special Educational Needs (SEN) programs offer additional support at school to students who meet a number of eligibility criteria that are assessed by teachers and psychologists. (DfE $(2010))$. Achievement in tests by a cohort of students is correlated with their assignment to these programs, as well as to the assignment by subsequent cohorts (Sartarelli and Tampieri (2011)).
} 
where the school strategy is:

$$
\begin{gathered}
t_{H P}=t_{H N}=\frac{c}{y \eta_{H 2}}, \\
t_{L P}=t_{L N}=\frac{c}{y\left(1-\eta_{L 2}\right)},
\end{gathered}
$$

and the student's strategy is:

$$
\begin{gathered}
e_{H P}=\frac{\left(1-\eta_{H 1}\left(1-e_{H}\right)\right)\left(\eta_{H 2}-1\right)(\mu-w)+q}{\left(1-\eta_{H 1}\left(1-e_{H}\right)\right) \eta_{H 2}(\mu-w)}, \\
e_{H N}=\frac{\left(1-e_{H}\right)\left(1-\eta_{H 2}\right) \eta_{H 1}(\mu-w)-q}{\left(e_{H}-1\right) \eta_{H 2} \eta_{H 1}(\mu-w)} \\
e_{L P}=\frac{q}{\left(1-\eta_{L 1}\right)\left(1-\eta_{L 2}\right) e_{L 1}(\mu-w)} \\
e_{L N}=\frac{q}{\left(1-\eta_{L 2}\right)(\mu-w)}
\end{gathered}
$$

Proof. See Appendix

Note that the school teaching strategy changes according to the student's ability but not according to scores in the first test.

\subsection{Analysis of equilibrium}

We turn now to study the properties of the equilibrium, by examining how performance targets influence the students'effort in equilibrium.

Corollary 1 (i)First-test performance target. As the first-test performance target increases, $e_{H P}$ and $e_{L P}$ increases, $e_{H N}$ decreases and $e_{L N}$ is not affected.

(ii)Second-test performance target. If

$$
\eta_{H 1}>\frac{\mu-w-q}{\left(1-e_{H}\right)(\mu-w)}
$$

then the effort $e_{H P}$ increases as the second-test performance target increases. If

$$
\eta_{H 1}<\frac{q}{\left(1-e_{H}\right)(\mu-w)}
$$

then the effort $e_{H N}$ increases as the second-test performance target increases. As the secondtest performance target increases, both $e_{L P}$ and $e_{L N}$ increases, $t_{H P}$ and $t_{H N}$ decrease while $t_{L P}$ and $t_{L N}$ increase.

Proof. Differentiation of $e_{H P}$ with respect to $\eta_{H 1}$ and $\eta_{H 2}$ yields

$$
\frac{\partial}{\partial \eta_{H 1}} e_{H P}=\frac{q\left(1-e_{H}\right)}{\left(1-\left(1-e_{H}\right) \eta_{H 1}\right)^{2} \eta_{H 2}(\mu-w)}>0
$$


and

$$
\frac{\partial}{\partial \eta_{H 2}} e_{H P}=\frac{\left(1-\left(1-e_{H}\right) \eta_{H 1}\right)(\mu-w)-q}{\left(1-\left(1-e_{H}\right) \eta_{H 1}\right)^{2} \eta_{H 2}(\mu-w)}
$$

which is positive iif $\eta_{H 1}>(\mu-w-q) /\left(1-e_{H}\right)(\mu-w)$. Differentiation of $e_{H N}$ with respect to $\eta_{H 1}$ and $\eta_{H 2}$ yields:

$$
\frac{\partial}{\partial \eta_{H 1}} e_{H N}=-\frac{q}{\left(1-e_{H}\right) \eta_{H 1}^{2} \eta_{H 2}(\mu-w)}<0
$$

and

$$
\frac{\partial}{\partial \eta_{H 2}} e_{H N}=-\frac{\left(1-e_{H}\right) \eta_{H 1}(\mu-w)-q}{\left(1-e_{H}\right) \eta_{H 1}^{2} \eta_{H 2}(\mu-w)}
$$

which is positive iif $\eta_{H 1}<q /\left(1-e_{H}\right)(\mu-w)$. Differentiation of $e_{H N}$ with respect to $\eta_{H 1}$ and $\eta_{H 2}$ yields:

$$
\frac{\partial}{\partial \eta_{H 1}} e_{H N}=-\frac{q}{\left(1-e_{H}\right) \eta_{H 1}^{2} \eta_{H 2}(\mu-w)}<0
$$

and

$$
\frac{\partial}{\partial \eta_{H 2}} e_{H N}=-\frac{\left(1-e_{H}\right) \eta_{H 1}(\mu-w)-q}{\left(1-e_{H}\right) \eta_{H 1}^{2} \eta_{H 2}(\mu-w)}
$$

which is positive iif $\eta_{H 1}<q /\left(1-e_{H}\right)(\mu-w)$. Differentiation of $e_{L P}$ with respect to $\eta_{L 1}$ and $\eta_{L 2}$ yields:

$$
\frac{\partial}{\partial \eta_{L 1}} e_{L P}=\frac{q}{e_{L}\left(1-\eta_{L 1}\right)^{2}\left(1-\eta_{L 2}\right)(\mu-w)}>0
$$

and

$$
\frac{\partial}{\partial \eta_{L 2}} e_{L P}=\frac{q}{e_{L}\left(1-\eta_{L 1}\right)\left(1-\eta_{L 2}\right)^{2}(\mu-w)}>0
$$

Differentiating $e_{L N}$ with respect to $\eta_{L 1}$ and $\eta_{L 2}$ yields:

$$
\frac{\partial}{\partial \eta_{L 1}} e_{L N}=\frac{q}{\left(1-\eta_{L 2}\right)^{2}(\mu-w)}>0
$$

and

$$
\frac{\partial}{\partial \eta_{L 2}} e_{L N}=0
$$

Corollary 1 shows that, given the same student's ability, a change in the current performance target influences the future students' effort according to whether student passes the test today. In addition, a change in the current performance target has a different effect on the current effort level for students with a different score in the previous test. A higher current performance target increases the current teaching effort by the school for low-ability students, as proxied by the score in the first test, while it decreases the teaching effort for high-ability ones. We then analyse how an increase in government funding may affect the students' effort.

Corollary 2 An increase in government funding per student increases the current studying effort. 
Proof. Differentiating $e_{H P}, e_{H N}, e_{L P}$ and $e_{L N}$ with respect to $w$ yields

$$
\begin{gathered}
\frac{\partial}{\partial w} e_{H P}=\frac{q}{\left(1-\eta_{H 1}\left(1-e_{H}\right)\right) \eta_{H 2}(\mu-w)^{2}}>0, \\
\frac{\partial}{\partial w} e_{H N}=\frac{q}{\left(1-e_{H}\right) \eta_{H 1} \eta_{H 2}(\mu-w)^{2}}>0 \\
\frac{\partial}{\partial w} e_{L P}=\frac{q}{e_{L}\left(1-\eta_{L 1}\right)\left(1-\eta_{H 2}\right)(\mu-w)^{2}}>0 \\
\frac{\partial}{\partial w} e_{L N}=\frac{q}{\left(1-\eta_{H 2}\right)(\mu-w)^{2}}>0 .
\end{gathered}
$$

\subsection{Analysis of test scores}

We now assess the effect of government funding programs on students' test scores and whether this differs by performance target thanks to the cross derivatives of test scores with respect to performance targets $\eta_{H 2}, \eta_{L 2}$ and government financial support $w$. We define the test score as the probability $\operatorname{Prob}(P)=T S_{i z}=e_{i} v_{i j} t_{i z}$ that a student passes the test. Given Proposition 1 , the corresponding tests scores are:

$$
\begin{gathered}
T S_{H P}=\frac{c}{y \eta_{H 2}}\left(\frac{\left(\left(1-\eta_{H 1}\left(1-e_{H}\right)\right)\left(\eta_{H 2}-1\right)(\mu-w)+q\right)\left(1-\eta_{H 2}\right)}{\left(1-\eta_{H 1}\left(1-e_{H}\right)\right) \eta_{H 2}(\mu-w)}+\eta_{H 2}\right), \\
T S_{H N}=\frac{c}{y \eta_{H 2}}\left(\frac{\left(\left(1-e_{H}\right)\left(1-\eta_{H 2}\right) \eta_{H 1}(\mu-w)-q\right)\left(1-\eta_{H 2}\right)}{\left(e_{H}-1\right) \eta_{H 2} \eta_{H 1}(\mu-w)}+\eta_{H 2}\right), \\
T S_{L P}=\frac{c}{y\left(1-\eta_{L 2}\right)}\left(\frac{q \eta_{L 2}}{\left(1-\eta_{L 1}\right)\left(1-\eta_{L 2}\right) e_{L 1}(\mu-w)}\right), \\
T S_{L N}=\frac{c}{y\left(1-\eta_{L 2}\right)}\left(\frac{q \eta_{L 2}}{\left(1-\eta_{L 2}\right)(\mu-w)}\right) .
\end{gathered}
$$

Proposition 2 shows how a change in government funding influences test scores.

Proposition 2 An increase in government funding per student increases the current test scores for low performance target and decrease it for high performance targets.

Proof. Differentiating $T S_{H P}$ and $T S_{H N}$ with respect to $\eta_{H 2}$ and $w$ yields

$$
\begin{gathered}
\frac{\partial^{2}}{\partial \eta_{H 2} \partial w} T S_{H P}=-\frac{c q}{\left(1-\left(1-e_{H 1}\right)\right) \eta_{H 2}^{2}(\mu-w)^{2} y}<0, \\
\frac{\partial^{2}}{\partial \eta_{H 2} \partial w} T S_{H N}=-\frac{c q}{\left(1-e_{H 1}\right) \eta_{H 2}^{2}(\mu-w)^{2} y}<0,
\end{gathered}
$$


Differentiating $T S_{L P}$ and $T S_{L N}$ with respect to $\eta_{L 2}$ and $w$ yields

$$
\begin{gathered}
\frac{\partial^{2}}{\partial \eta_{L 2} \partial w} T S_{L P}=\frac{c q\left(1+\eta_{L 2}\right)}{e_{L 1}\left(1-\eta_{L 1}\right)\left(1-\eta_{L 2}\right)^{3}(\mu-w)^{2} y}>0 \\
\frac{\partial^{2}}{\partial \eta_{L 2} \partial w} T S_{L N}=\frac{c q\left(1+\eta_{L 2}\right)}{\left(1-\eta_{L 2}\right)^{3}(\mu-w)^{2} y}>0
\end{gathered}
$$

Differentiating $T S_{H P}$ and $T S_{H N}$ with respect to $\eta_{H 1}$ and $w$ yields:

$$
\begin{gathered}
\frac{\partial^{2}}{\partial \eta_{H 1} \partial w} T S_{H P}=\frac{c q\left(1-e_{H 1}\right)}{\left(1-\left(1-e_{H 1}\right) \eta_{H 1}\right)^{2} \eta_{H 2}(\mu-w)^{2} y}>0 \\
\frac{\partial^{2}}{\partial \eta_{H 1} \partial w} T S_{H N}=-\frac{c q}{\left(1-e_{H 1}\right) \eta_{H 1}^{2} \eta_{H 2}(\mu-w)^{2} y}<0
\end{gathered}
$$

Differentiating $T S_{L P}$ and $T S_{L N}$ with respect to $\eta_{L 1}$ and $w$ yields

$$
\begin{gathered}
\frac{\partial^{2}}{\partial \eta_{L 1} \partial w} T S_{L P}=\frac{c q \eta_{L 2}}{e_{L 1}\left(1-\eta_{L 1}\right)^{2}\left(1-\eta_{L 2}\right)^{2}(\mu-w)^{2} y}>0 \\
\frac{\partial^{2}}{\partial \eta_{L 1} \partial w} T S_{L N}=0
\end{gathered}
$$

Proposition 2 shows a positive relationship between government financial support and test scores.

\section{Conclusion}

We analysed whether meeting performance targets in education has an effect on students' subsequent achievement in compulsory education and the take-up by schools of financial support from the government for students with certain characteristics. We built a theoretical model to describe how students' belief of their ability, that is proxied by by previous performance in tests, affects their current effort to pass a test, and also how targets affect the effort that schools put in teaching. An increase in the performance target in the first test has an ambiguous effect on the effort by students in the second test. An increase in the performance target in the current test increases the effort of low-ability students and teaching effort for low ability students, while it has an ambiguous effect on high ability ones. Finally, an increase in government funding per student increases the current effort by students.

In the design of education policies a government sets among other rules those over the content and the marking of tests for students in schools, and the disclosure of test scores to students and their parents. It may also wish to encompass incentives for schools and devices that help policy-makers to learn whether and why students in certain schools obtain higher scores than students in other schools, such as performance targets in tests. Hence, a government may face 
a tradeoff. A simple policy that only focuses on the administration of tests is easy to implement but it may not be helpful to help policy-makers learning more about schools with high or low performances. Viceversa, a policy that also sets incentives for schools and summarises the performance by schools may appear to deliver more than a simple policy, but it may also be difficult to implement.

Promoting incentives in schools, e.g. test-based accountability, may lead to effects that were unintended by a policy-maker at the design stage of a policy. In education policies performance targets were designed to influence school choice by students and the allocation of funding to schools by the government. The paper shows that changes in such targets also modify the incentives by teachers, who may devote more effort on students with certain characteristics than on others. Future research assessing the effect of targets in the delivery of services other than education, such as health or social services, may offer useful evidence for policy-makers' decisions on contracts and the allocation of resources for teachers, as well as for employees in other areas in the public sector. 


\section{References}

Acemoglu, D. and Pischke, J. S. (2001). Changes in the wage structure, family income, and children's education. European Economic Review, 45 (4-6), 890-904.

Azmat, G. and IriberRi, N. (2009). The Importance of Relative Performance Feedback Information: Evidence from a Natural Experiment using High School Students. CEP Discussion Papers dp0915, Centre for Economic Performance, LSE.

Bandiera, O., Larcinese, V. and Rasul, I. (2009). Blissful Ignorance? Evidence From a Natural Experiment on The Effect of Individual Feedback on Performance. mimeo, University College London.

Chevalier, A. and Lanot, G. (2002). The relative effect of family characteristics and financial situation on educational achievement. Education Economics, 10 (2), 165-181.

Crawford, C. and Vignoles, A. (2010). An analysis of the educational progress of children with special educational needs. DoQSS Working Papers 10-19, Department of Quantitative Social Science - Institute of Education, University of London.

Cullen, J. B. and Reback, R. (2006). Tinkering Toward Accolades: School Gaming Under a Performance Accountability System. Working Paper 12286, National Bureau of Economic Research.

Currie, J. and Moretti, E. (2003). Mother's education and the intergenerational transmission of human capital: Evidence from college openings. Quarterly Journal of Economics, 118 (4), 1495-1532.

DFE (2010). Local education authority gateway. http://webarchive.nationalarchives.gov.uk/ $20040104233549 /$ dfes.gov.uk/leagateway/.

Figlio, D. N. and Getzler, L. S. (2002). Accountability, Ability and Disability: Gaming the System. NBER Working Papers 9307, National Bureau of Economic Research, Inc.

Gary-Bobo, R. J. and Trannoy, A. (2008). Efficient tuition fees and examinations. Journal of the European Economic Association, 6 (6), 1211-1243.

Prendergast, C. (1999). The provision of incentives in firms. Journal of Economic Literature, 37 (1), 7-63.

Rourke, E. and F., I. (1991). Educational testing service. International Directory of Company Histories.

Sartarelli, M. (2011). Do Performance Targets Affect Behaviour? Evidence from Discontinuities in Test Scores in England. DoQSS Working Papers 11-02, Department of Quantitative Social Science - Institute of Education, University of London.

— and TAMPIERI, A. (2011). Do performance targets in tests affect future actions by schools? Evidence from discontinuities in test scores. mimeo, Institute of Education. 


\section{Appendix}

\section{Proof of Proposition 1}

We solve the mixed strategy by backward induction, we thus start from the second stage where students decide their effort in order to take the second test.

Students. If the student exerted effort and passed the first test, her expected payoff is:

$$
S\left(e_{i}=1, e_{i H}=1\right)=\frac{\lambda e_{H}\left(y t_{H P}-c\right)+(1-\lambda) e_{L}\left(1-\eta_{L 1}\right)\left(y t_{L P}\left(1-\eta_{L 2}\right)-c\right)}{\lambda e_{H}+(1-\lambda) e_{L}\left(1-\eta_{L 1}\right)},
$$

if the student exerts effort for the second test and:

$$
S\left(e_{i}=1, e_{i H}=0\right)=\frac{\lambda e_{H} y t_{H P}\left(1-\eta_{H 2}\right)}{\lambda e_{H}+(1-\lambda) e_{L}\left(1-\eta_{L 1}\right)},
$$

if she shirks. The indifference condition is given by:

$$
S\left(e_{i}=1, e_{i j}=1\right)=\left(e_{i}=1, e_{i j}=0\right)
$$

If the student shirked and failed the first test, her expected payoff is:

$$
S\left(e_{i}=1, e_{i N}=0\right)=\frac{\lambda\left(1-e_{H}\right) \eta_{H 1}\left(y t_{H P}-c\right)+(1-\lambda)\left(1-e_{L}\right)\left(y t_{L P}\left(1-\eta_{L 2}\right)-c\right)}{\lambda\left(1-e_{H}\right) \eta_{H 1}+(1-\lambda)\left(1-e_{L}\right)}
$$

if the student exerts effort and:

$$
S\left(e_{H P}=0\right)=\frac{\lambda\left(1-e_{H}\right) \eta_{H 1} y t_{H P}\left(1-\eta_{H 2}\right)}{\lambda\left(1-e_{H}\right) \eta_{H 1}+(1-\lambda)\left(1-e_{L}\right)}
$$

if she shirks. The indifference condition is given by:

$$
S\left(e_{i}=1, e_{i N}=1\right)=S\left(e_{i}=1, e_{i N}=0\right) .
$$

If the student shirked and passed the first test, she knows that she has high ability. Her expected payoff is:

$$
S\left(e_{H}=1, e_{H P}=1\right)=y t_{H P}-c,
$$

if the student exerts effort and:

$$
S\left(e_{H}=1, e_{H P}=0\right)=y t_{H P}\left(1-\eta_{H 2}\right),
$$

if she shirks. The indifference condition is given by:

$$
S\left(e_{H}=1, e_{H P}=1\right)=S\left(e_{H}=1, e_{H P}=0\right) .
$$

If the student exerted effort and failed the first test, she knows that she has low ability. 
Her expected payoff is:

$$
S\left(e_{L}=1, e_{L F}=1\right)=\left(1-\eta_{L 2}\right) y t_{H P}-c,
$$

if the student exerts effort and:

$$
S\left(e_{H}=1, e_{H P}=0\right)=y t_{H P}\left(1-\eta_{H 2}\right),
$$

if she shirks. The indifference condition is given by:

$$
S\left(e_{H}=1, e_{H P}=1\right)=S\left(e_{H}=1, e_{H P}=0\right) .
$$

Solving (1), (2), (3) and (4) by $t_{H P}, t_{H L}, t_{L P}$ and $t_{L N}$ we obtain the strategy depicted in Proposition 1.

School. To begin with, note that, in the case that school does not give any teaching to a student, her expected payoff of exerting effort is always negative, since the cost of studying without any support from the school is too high and as a consequence shirking is a strictly dominant strategy fort the student. It follows that the school obtains full government funding for a student in the case of no teaching at all.

If the student has high ability and passed the first test, the school expected payoff $\Pi\left(t_{H P}=1\right)$ is

$$
\lambda\left(e_{H}+\left(1-e_{H}\right)\left(1-\eta_{H 1}\right)\right)\left(\left(\left(e_{H P}+\left(1-e_{H P}\right)\left(1-\eta_{H 2}\right)\right) \mu+\left(1-e_{H P}\right) \eta_{H 2} w\right)-q\right),
$$

if it exerts teaching effort and

$$
\Pi\left(t_{H P}=0\right)=\lambda\left(e_{H}+\left(1-e_{H}\right)\left(1-\eta_{H 1}\right)\right) w
$$

if it does not. The indifference condition is given by:

$$
\Pi\left(t_{H P}=1\right)=\Pi\left(t_{H P}=0\right) .
$$

Solving by $e_{H P}$, we obtain the result depicted in Proposition 1.

If the student has high ability and failed the first test, the school expected payoff $\Pi\left(t_{H N}=1\right)$ is

$$
\lambda\left(\left(1-e_{H}\right) \eta_{H 1}\right)\left(\left(\left(e_{H N}+\left(1-e_{H N}\right)\left(1-\eta_{H 2}\right)\right) \mu+\left(1-e_{N}\right) \eta_{H 2} w\right)-q\right),
$$

if it exerts teaching effort and

$$
\Pi\left(t_{H N}=0\right)=\lambda\left(\left(1-e_{H}\right) \eta_{H 1}\right) w,
$$


if it does not. The indifference condition is given by:

$$
\Pi\left(t_{H N}=1\right)=\Pi\left(t_{H N}=0\right) .
$$

Solving by $e_{H N}$, we obtain the result depicted in Proposition 1.

If the student has low ability and passed the first test, the school expected payoff $\Pi\left(t_{L P}=1\right)$ is

$$
(1-\lambda)\left(e_{L}\left(1-\eta_{L 1}\right)\right)\left(\left(\left(e_{L P}\left(1-\eta_{L 2}\right)\right) \mu+\left(e_{L P} \eta_{L 2}+\left(1-e_{L P}\right)\right) w\right)-q\right),
$$

if it exerts teaching effort and

$$
\Pi\left(t_{L P}=0\right)=(1-\lambda)\left(e_{L}\left(1-\eta_{L 1}\right)\right) w,
$$

if it does not. The indifference condition is given by:

$$
\Pi\left(t_{L P}=1\right)=\Pi\left(t_{L P}=0\right) .
$$

Solving by $e_{L P}$, we obtain the result depicted in Proposition 1.

If the student has low ability and failed the first test, the school expected payoff $\Pi\left(t_{L N}=1\right)$ is

$$
(1-\lambda)\left(e_{L} \eta_{L 1}+\left(1-e_{L}\right)\right)\left(\left(\left(e_{L N}\left(1-\eta_{L 2}\right)\right) \mu+\left(e_{L N} \eta_{L 2}+\left(1-e_{L N}\right)\right) w\right)-q\right),
$$

if it exerts teaching effort and

$$
\Pi\left(t_{L N}=0\right)=(1-\lambda)\left(e_{L} \eta_{L 1}+\left(1-e_{L}\right)\right) w
$$

if it does not. The indifference condition is given by:

$$
\Pi\left(t_{L N}=1\right)=\Pi\left(t_{L N}=0\right) .
$$

Solving by $e_{L N}$, we obtain the result depicted in Proposition 1. 


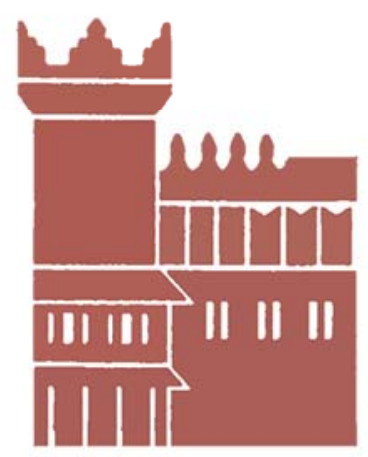

Alma Mater Studiorum - Università di Bologna DEPARTMENT OF ECONOMICS

Strada Maggiore 45

40125 Bologna - Italy

Tel. +39051 2092604

Fax +390512092664

http://www.dse.unibo.it 